\title{
Critical perspectives on language planning and policy in Africa: Accounting for the notion of multilingualism
}

\author{
Felix Banda \\ Linguistics Department, University of the Western Cape, Private Bag X17, Bellville 7535, South Africa \\ E-mail: fbanda@uwc.ac.za
}

\begin{abstract}
This paper draws on the notion of multilingualism as social practice (Heller 2007) to critique postcolonial language planning and policies in Africa. Drawing on illustrations from Ethnologue's (2009) languages of Africa, studies on language planning and policy in Africa, and recent developments in harmonisation of cross-border language research (Prah 1998; Banda 2008), the paper argues that there are distortions in the conceptualisation of multilingualism and what it entails in Africa's socio-cultural contexts. In turn, the paper faults monolingual biases in the notions and models used to describe and promote multilingualism in Africa, which mirror descriptions of the language situation in Western socio-cultural contexts. The paper argues for cross-linguistic and cross-border status and corpus planning to take advantage of multilingualism as a linguistic resource for socioeconomic development in Africa. The paper concludes by highlighting the prospects for linguistic repertoire-based multilingual models for language planning and policy in Africa.
\end{abstract}

Keywords: multilingualism, language policy, linguistic repertoire, urbanization, postcolonial

\section{Introduction}

The aim of the paper is to critique the monolingual characterisation that has informed language planning and policy in Africa. This entails an exploration of the utility of certain language planning and policy pronouncements, as well as models arising out of these. In this regard, the efficacy of notions such as 'additive multilingualism' as well as the categorisation of some languages as "official" and others as "non-official" are discussed in relation to multilingualism in late modern contexts. The paper contends that one of the main drawbacks of current policy is that it is still based on Western and colonial notions of multilingualism, which basically involves multiple monolingualisms. On this view, for instance, promotion of multilingualism in South Africa is erroneously seen as a case of promoting 11 monolingual streams of distinctive languages in their equally homogenous speech communities, and bilingualism is paradoxically said to arise through education using a singular language (albeit the mother tongue). Given the monolingual orientation in language planning and policy in Africa, it is not surprising that in the majority of cases colonial languages have retained their official status and are the main languages of education, state functions and business in general (Heugh 2006; Rassool 2006). 
Peirce and Ridge (1997) lament the dearth of material in language planning research in Africa, except for South Africa. However, even in South Africa there has been a preoccupation with the mother tongue debate, rather than with establishing how African languages can be harnessed into an integrated multilingual teaching programme. As regards the former (i.e. speakers' mother tongues), an African child is often said to have a singular "mother tongue", which is seen as in opposition to other African tongues spoken in the region or nation. The danger here is that African languages which have existed side by side for significant periods of time, complementing and supplementing each other in multilingual symbiosis, are suddenly cast as competing for spaces. Additionally, multilingual African communities are then erroneous characterised as made up of distinctive monolingual enclaves.

Motivated by the language rights paradigm and linguistic human rights activists, the mother tongue debate has further been fuelled by some linguistic imperialist arguments (Phillipson 1992) pertaining specifically to the global dominance of English. As stated by Phillipson (1992: 1), in essence "the British Empire has given way to the empire of English." One major component of the notion of linguistic imperialism is cultural domination of Africans through education in English. The problem is that the argument about how to improve and integrate African languages into education is then overshadowed by arguments about the detrimental effects on African languages and cultures as result of using English as medium of instruction and in other domains of socio-economic development in Africa. Both the mother tongue debate and linguistic imperialist arguments find focus in the perceived "sanctity" of monolingualism and monoculturalism. In other words, contact with English necessarily leads to English monolingualism. Multilingualism and multiculturalism are thus inadvertently discounted as viable options. Resources and donor-funded projects on the detrimental effects of colonial languages in the education of Africans abound, while very little attention is given to developing indigenous African languages as languages of education and modernity, not merely as languages of "culture" and "tradition". In fact, in African countries, funding is often poured into ceremonies celebrating African "culture" and "tradition" at the expense of establishing research facilities for the development of African languages (i) as viable alternatives to English and other colonial languages and (ii) as languages of education, the economy and modernity. In this paper, I will argue that, currently, the basic philosophy and ideology regarding language education policy in Africa is informed by monolingualism and is not so different from the policy promoted by colonialists. Furthermore, I will argue that there is a need to explore models in which two or more languages are used as media of instruction. Current models focus on one language, while the other languages are seen as optional "additional" languages.

\section{Multilingualism and the colonial legacy and ideology in Africa}

\subsection{African languages for tradition and culture}

Despite the fact that, after independence, most African countries recognised several languages as official languages, classroom practice and official government functions remain the domain of colonial languages. For instance, in Zambia, seven regional languages and in South Africa 11 regional languages have national or official status, but English has retained its position as the main language of education, government and business. The linguistic influence of the official African languages is mostly confined to the same regions to which the colonial governments had assigned them, mostly for administrative convenience. In the case of former British colonies such as Zambia and Kenya, the "regional" linguistic borders served the 
colonial government's divide-and-rule policy well, as they were further divided into "tribal" or "ethnic" villages. Even though Zambia is one of the most urbanised countries in Africa, the National Registration Card (which is what a Zambian identity document is called) has the name of the chief and village on it. In essence, every person should be under the jurisdiction of a chief and should be domiciled in a village, so that their stay in urban areas, or wherever they reside, is supposed to be temporary. This state of affairs was created by colonialists to keep Africans out of the developed urban areas, where non-Europeans would only venture for work purposes. In fact, one of the most enduring legacies of colonialism is the image of a happy African who has his roots in a tribe and traditional village, practising his own culture and traditional rituals, and using his own language. Furthering the notion of the Tower of Babel, the language he speaks is perceived to be incomprehensible to neighbouring communities who have their own tongues. For unexplained reasons, phenomena related to language contact, where speakers of different languages tend to congregate in "areas of linguistic confluence" (Gough 1994: 11), are portrayed by some to be non-existent in Africa. My argument is that this notion of a cultured traditional Africa is no longer tenable, since the idea that Africa is made up of a myriad of unrelated languages has been shown to be a farce (see Prah 1998; Banda 2008). For instance, most of the languages in Southern Africa belong to the Bantu language group, which can further be divided into sub-groups or clusters with more or less similar morphological and phonological features, and hence with varying degrees of mutual intelligibility. Consider the case of South Africa, for example: Even though the country has 11 official languages, the majority of Africans speak either Nguni or TswanaSotho dialects. In terms of language planning and terminological development and orthographic design, there is no linguistic reason why, say, isiXhosa, isiZulu, Ndebele and Seswati should be developed as unrelated linguistic systems (cf. Jokweni 2003). Careful language planning and cross-linguistic referencing would enable these languages to share a large amount of teaching and reading material, as well as readership.

The argument is that African language policy and planning is not only constructed in the image of Western countries (Anchimbe 2007), but also retains the colonial heritage which directly associates African languages to (ethnic) tradition and culture, rather than socioeconomic development and mobility.

Therefore, three observations can be made. Firstly, African languages are promoted as autonomous and bounded systems linked to equally autonomous homogenous communities, regions and, in some cases, far flung villages. Secondly, even though there is evidence of multilingual speech patterns all over Africa, the official doctrine is to promote singular languages to the exclusion of other African languages spoken in the communities or regions. Thirdly, even though English and other colonial languages are part of the multilingual landscape and have become critical components of the linguistic repertoires of Africans (due, in part, to the advent of information technology), the policies favoured by language education researchers are those that restrict instruction in English to later stages of a child's education (see Banda 2000; Williams 2008; Heugh 2005, 2006). In practice, this would mean replacing mother-tongue based monolingual education with English-based monolingual education, both of which are incompatible with the multilingual discourse practices that characterise the late modern multilingual spaces of Africa (cf. Banda 2009a).

\subsection{Resisting Westernisation of African knowledge systems}

Shi-xu (2007), Asante (2006) and others have warned against wholesale Westernisation of knowledge, particularly when it is to the detriment of local knowledge systems. The need for 
hybridity and for individuals able to communicate across ethnic boundaries and speech communities, and in different social networks and modalities in late modern times means appropriating and adapting Western knowledge to local conditions. In essence, this means that there is a place for both African languages and English in the repertoires of late modern Africans. After all, most Western knowledge is currently stored in English. This point has not been lost on African parents who demand education in English for their children from day one at school, or as soon as possible thereafter (Banda 2000, 2003, Heugh 2006). Parental aspirations are thus in direct opposition to those of language education researchers, who advocate for education in the mother tongue, or at least in an African language, in the early years of a child's education.

However, the very notion of 'mother tongue' is problematic in late modern times where urbanisation, hybridization and multilingualism are the rule rather than the exception, even in Europe (Appadurai 1996). I would like to argue that, in late modern multilingual African societies, rather than "a mother tongue", there are "mother tongues" that constitute speakers' linguistic repertoires. In essence, my argument is that there are individual, community, regional or national and, increasingly, transnational linguistic repertoires that should guide the design of multilingual education models (Banda 2009a). Monolingualism, even mother tongue-based monolingualism, is not ideal. In other words, a monolingual model which champions the mother tongue in multilingual contexts of Africa is wasteful, as not all knowledge embedded in the repertoire of speakers is utilized. Thus, rather than developing, for instance, Zulu, Sotho and English as linguistic repertoires of people in Johannesburg, Pretoria and other regions/provinces, the trend in South Africa is to develop these languages as autonomous language systems belonging to different monolingual speech communities, each with its own language. I return to my conceptualisation of 'linguistic repertoires' later.

Anchimbe (2007) laments the fact that in spite of gaining independence, postcolonial linguistics studies, as well as language education policy in Africa, have been designed on the basis of theories, platforms, templates and frameworks constructed in and for the West, with design features for a monolingual speaker living in a more or less homogenous society. (However, as noted earlier, even in the West such an individual is becoming a rarity.) In this regard, Banda (2008) argues that despite their noble intentions, missionaries and other Europeans who worked on writing systems for African languages often caused imperfections in the written form of these languages because they have based such writing systems on the characteristics of the writing systems of European languages. For instance, native speakers of Nyanja (mostly spoken in Zambia and Malawi) only have the [1] sound, but missionaries introduced both $l$ and $r$ in the written form (Banda 2008), thus necessitating the morphological rule, in the written form only, that $r$ should be used before the high vowels [i, e]. But this is not applied consistently, as there is a counter rule which states that $l$ should be used before letters $i$ and $e$ if it is the initial letter of the stem of a word. In reading, native speakers pronounce $r$ as [1], since pronouncing the [r] sound is associated with a European missionary or a child who is still in the process of learning to speak the language (Banda 2008). Thus, the rules are illogical and difficult to teach to mother tongue speakers (Banda 2008).

On the other hand, Anchimbe (2007) points out that what constitutes language and community has also been distorted by the imposition of European templates. Anchimbe (2007) further argues that the distorting impact of foreign models has kept researchers from investigating peculiar characteristics of African societies as outcomes of their socio-historical 
totality. For instance, describing Africa's multilingualism as being equivalent to European multilingualism is theoretically misleading and has often led to the adoption of policies and models which are impractical in African contexts (Makoni 1998a, 1998b; Banda 2000). In South Africa, the promotion of multilingualism is in practice (mis)taken to involve the promotion of 11 autonomous monolingual programmes/systems, that is, as a case of multiple monolingualisms (Banda 2009a).

Myers-Scotton (1993), after extensive research in Africa, concludes that speaking more than one language in one conversation in one day is the rule rather than the exception in Africa. In fact, Schmied (1991) shows that the English code is an important component of Africa's multilingual landscapes. In other words, any model that champions a single language as language of instruction would not be in sync with the linguistic situation and the frame of social networks of language usage in Africa. The following are some of the characteristic differences between multilingualism in Africa and multilingualism in the West:

(i) In the West, one can survive with one language; in Africa, this is virtually impossible.

(ii) In spite of the European Union, there are still distinctive borders, more or less geographically aligned with linguistic borders (e.g. France, Russia, England, Belgium [Flemish Flanders and French Walloon], etc.). Most African languages tend to cross geographical borders (Prah 1998).

(iii) Knowing and speaking more than one language in one conversation in one day is the rule rather than the exception in Africa (Myers-Scotton 1993) but not necessarily in the West.

(iv) In the West, research and planning for multilingualism often refer to the assimilation of immigrant/migrant families (Makoni 1998a, b; Anchimbe 2007).

(v) In Africa, multilingualism refers to related (Bantu) dialects, e.g. isiZulu, isiXhosa, Setswana, Sesotho, Nyanja, Nsenga, Bemba, etc.; in the West, multilingualism often involves unrelated languages such as English, Portuguese, French, German, Russian (particularly in relation to the languages of immigrants, such as Arabic, Hindi, Chinese, etc.).

(vi) In the West, monolingual communities live side by side; in Africa, bi-/multilingual (polyglot) communities live side by side (Schmied 1991; Myers-Scotton 1993).

(vii) In the West, bilingualism is the result of being taught a second language at school; in Africa, bilingualism is the norm, the way of life, and second languages are acquired naturalistically (Schmied 1991; Myers-Scotton 1993).

(viii) European multilingualism involves several written languages; the African context involves only one or two written languages existing alongside oral languages embedded in oral cultures and transmitted orally (Anchimbe 2007).

(ix) In the West, the language used in the home is often the one used in the school and in workplaces, whereas this is often not the case in Africa (Anchimbe 2007).

The argument here is that models and language development strategies, suitable for Western countries with the monolingual speaker at their centre, are inadvertently applied to African contexts with the multilingual speaker at their centre. For instance, the notion of 'additive bilingualism/multilingualism' makes sense when a language is "added" to a monolingual speaker's repertoire, but not when it is added to the linguistic repertoire of a person who is already bi-/multilingual. Additive bilingualism is sometimes understood to mean 6 to 7 years of mother tongue education before a switch to English medium of instruction for African learners. The assumption is that 6 to 7 years of mother tongue education will enable learners 
to have acquired the cognitive competence required to handle the teaching/learning of content in their second language English (see Williams 2008 for an extended critique of this practice). Makoni (1998a) has been critical of the uncritical manner in which the notion of additive bilingualism has been applied in African multilingual contexts:

Notions of additive bilingualism when applied to Africans learning English reinforce the position of English as a dominant language. The subtext of the additive model in Africa is that when Africans have reached a 'threshold level' they can acquire English. (Makoni 1998a: 161)

Consolidation of proficiency in an African language first in order to enable successful acquisition of English is clearly counterproductive, particularly when the aim is to promote the status of African languages as viable alternatives to English in education.

\subsection{Linguistic repertoires and models of education}

Based on the monolingual perception of a direct relationship between language and identity, the failure of imported models of education is crystallised in the language planning and policies in African education, which are pursuing a monolingual agenda. The language policies and the models that they spawn are designed for a monolingual child and his vernacular/mother tongue, or a child and his second language English. The models take an "either/or" approach when, in fact, the two languages are both important, and thus both need to be developed as part of the child's linguistic repertoire. I use the term "linguistic repertoire" in the same sense as "code repertoire" (Kachru 1990: 58), "verbal repertoire" and "communicative repertoire" (Hymes 1974; Gumperz and Hymes 1972) with reference to a bilingual speaker. I use "linguistic repertoires" to refer to the total range of codes available to the bilingual speaker which enable him to perform different roles across ethnic, community, regional and national boundaries, and across modalities, styles and registers. Thus, I perceive linguistic repertoires as operating not merely within, but also across social networks; not only within the context of the speech community, but also across heterogeneous and multidimensional localities, communities, regions and nations. In other words, the notion of linguistic repertoire involves more than a monolingual's language knowledge and more than monolingual competence in each of the codes in a multilingual's repertoire. In essence, comprehensive models of bilingualism in African countries, for example, need to account for the range of African languages and English and/or French, Portuguese, etc. spoken by African speakers. Rather than the pedagogy of a singular mother tongue, I argue for models that account for linguistic repertoires such as those referred to above.

\subsection{Distortions in official, regional and national language designations}

After independence, the emergent African states followed the "Western" tradition of labelling certain languages as "official" and others as "regional" or "national". The distinction between official and national languages is not always clear, as these are described differently by different countries. In practice, some of the languages designated as national languages are best described as "regional" languages, as they are restricted to regional use. This seems to be the case with the seven national languages of Zambia (Bemba, Nyanja, Lozi, Tonga, Luvale, Lunda and Kaonde), which are region-based and mostly used for cultural functions and occasionally in local governance, while English is used nationally in all official functions. In South Africa, official government functions are almost exclusively performed in English, even though on paper 11 languages have been given "official" language status. It is with this in mind that one should consider the following Ethnologue (2009) list of languages of Africa: 
- Angola: One official language (Portuguese); seven national languages; 42 listed languages (41 living, one extinct).

- $\quad$ Botswana: Two national/official languages (English and Tswana); 28 listed languages.

- Cameroon: Two official languages (French and English); 230 or 286 listed languages/dialects.

- Congo Democratic Republic: Five national/official languages (Koongo, Lingala, Luba-Kasai, Congo Swahili, French); 254 listed languages.

- $\quad$ Kenya: Two official languages (English and Kiswahili); 61 listed languages.

- Malawi: One official language (English); two national languages (Chichewa and Tumbuka); 14 listed languages.

- $\quad$ Mozambique: One official language (Portuguese); 43 listed languages.

- $\quad$ Namibia: One official language (English); 13 indigenous national languages; 28 listed languages.

- $\quad$ Nigeria: 10 national/official languages (English plus nine African languages); 521 listed languages (510 living, nine extinct; the status of the other two languages is not stated possibly because Ethnologue could not verify whether the languages are extinct or not).

- $\quad$ South Africa: 11 official languages (English plus 10 African languages - or, if one does not regard Afrikaans as an African language, then English, Afrikaans and nine African languages); 31 listed languages (24 living, four extinct; the status of the other three languages is not stated, perhaps for the reason given above).

- Tanzania: Two national/official languages (Kiswahili and English); 128 listed languages (127 living, one extinct).

- Zambia: One official language (English); seven national languages; 72 listed languages/dialects.

In almost all cases, the colonial languages became the official languages and, ironically, what should be regional indigenous languages are proclaimed national languages. The proclamation of languages as official, national and non-official imposes a power and status hierarchy not only among the languages, but also among the speakers of these languages. Material resources for the development and use of the languages depend on official designations, meaning that the colonial languages retain the monopoly in terms of national exposure in the media (private and parastatal) as well as in government communication. This has led to distortions in the multilingual landscapes of Africa as it becomes desirable, and even fashionable, for individuals to acquire colonial languages at the expense of local ones.

Moreover, if we ignore the designations of the languages and dialects above, we see the range of linguistic repertoires available to Africans. The fact that very few languages are listed as extinct, despite policies that appear designed for monolingualism, suggests that speakers use the official, national or regional languages but have also not abandoned indigenous languages which do not fall into these three categories. In other words, the multilingual repertoires of speakers contain codes of both officially recognised and unrecognised languages. This multilingual reality is unlikely to be captured by current models of language education.

There are also distortions arising from monolingual biases in census data. For instance, it is not always possible to determine the number of first, second, third, etc. language speakers of a particular language based on census data. The census data impose another restriction on the analysis of particular languages, as the collection of these data is often restricted to colonial 
geographical borders. It does not take into consideration speakers of the same language that reside across national borders. Consider the following list of the number of (first language) speakers of selected languages, as sourced from Ethnologue (2009):

- $\quad$ Luchazi: 155,000 in Angola; 54,400 in Zambia; total number of speakers: 209,400.

- $\quad$ Mbunda: 135,000 in Angola; 126,000 in Zambia; total number of speakers: 261, 000.

- $\quad$ Chokwe: 455,800 in Angola; 44,200 in Zambia; 504, 000 in Democratic Republic of the Congo; total number of speakers: 1,004,000.

- Luvale: 464,000 in Angola (not official/national language); 205,000 in Zambia (national language); total number of speakers: 669,000.

- $\quad$ Tumbuka: 392,000 in Zambia (not official/national language); 940,000 in Malawi (national language); total number of speakers: 1,332,000.

- $\quad$ Nyanja: 7,000,000 in Malawi; 599,000 in Mozambique; 803,000 in Zambia; 252,000 in Zimbabwe; total number of speakers 8, 654, 000.

It is worth noting that the total number of speakers of each of these languages in all countries, including those countries not listed here, is much higher. For instance, Chokwe is also spoken in Namibia and Nyanja is spoken in Botswana, South Africa and Swaziland, but these figures are not available (Ethnologue 2009). This serves to illustrate that the colonial geographical borders distort the magnitude of the number of speakers of these languages. The borders also appear to reduce the chances of official and national significance of some of the languages being considered major languages. For instance, Luchazi has 209,400 speakers scattered across Angola and Zambia but is not considered a national language in either of these countries. The same is true of Chokwe, which is spoken by more than half a million people in the Democratic Republic of the Congo and Zambia, but is not categorised as a major national language in either of the two countries. The case of Luvale is interesting, as it is spoken by more people in Angola (466, 000), where it is not a national language, than in Zambia (205, 000), where it is a designated national language. Tumbuka is spoken by more than 1 million people in Zambia and Malawi, and was only recently designated as a national language in Malawi; in Zambia, it remains an unrecognized language in terms of official status. Clearly, there are politics involved in awarding official or national status to languages, as the data suggest that such status is not awarded on the basis of the number of speakers and that other considerations come into play here.

Assuming that the above figures relate to first language speakers only, it is not clear how many people speak these languages as second, third, etc. languages. In most cases, census data report on how many people speak a language as their first language or as a "tribal" or "ethnic" language. The problem is that in multilingual contexts, defining a person's linguistic repertoire based on ethnic or home language is rather inadequate because of the translocations and diasporic nature of late modern African lifestyles. Moreover, it is not always possible to speak an ethnic or home language in all situations, as people tend to spend more time in their workplaces than at home. This leads to another distortion. Makoni, Brutt-Griffler and Mashiri (2007) argue that in urbanized multilingual contexts of Africa, people draw their identities not only from mother tongue ownership or pandering to rural "ethnic" identities, but more from their repertoires as diasporic multilingual urbanites. Similarly, Bemba and Nyanja are spoken by more people in Zambia than only those who call it their ethnic language (Banda 2008). In essence, the relationship between language use and ethnicity is not always a straightforward one, contrary to how it is depicted in literature on language policy and education. The argument is as follows: To take advantage of the large pool of first, second, third, etc. 
language speakers of these African tongues, language planning and policy needs to cross ethnic, regional and national borders. This would unlock a large market for books and other teaching material. In turn, this would attract publishers and investments in African languages, which are currently lacking. For instance, the large number of speakers of each of the languages listed above is first reduced by colonial borders and is further trimmed by national (effectively, regional) language planning which is premised on a monolingual and ethnic mother tongue speaker. All of these considerations call for a different conceptualization of multilingualism in Africa and the models which are meant to engender this.

\section{Concluding remarks: Towards alternative notions of multilingualism in Africa}

It is necessary to recognize that geographic, linguistic, ethnic, etc. borders are social constructs and not impermeable structures. Indeed, Appadurai (1996) notes that the structures that we perceive as constituting communities, localities, nations, etc. are in fact tools to stabilize objects that are in a state of flux. In this regard, it needs to be recognised that the colonial governments' motivation for erecting particular borders was to exercise power and control over people (Harries 2007).

There is also a need for the democratization of multilingual community spaces so as to enable hybridity and temporal and spatial identities to be exhibited through multiple languages/dialects. This entails weaning African multilingualism from distortions resulting from the colonial legacy and the pervasive monolingual descriptions that underlie models of language education.

Therefore, language planning and policy in Africa and comprehensive multilingual models arising from them need to account for:

(i) localized multilingual practices that are innovative enough to allow for cross-border language practices;

(ii) hybridity and urbanized, mobile, diasporic populations; and

(iii) the semiotically constituted spatial identities exhibited through multiple languages (Stroud 2008).

There is a need for multilingual models of education and language policies which are based on natural linguistic repertoires of the speakers concerned and for the cross-border configuration of such models and policies that account for border-crossing multilingual landscapes (Banda 2008, 2009a, 2009b). As demonstrated above, Africa is constituted of multilingual landscapes that cross national, ethnic, etc. borders. Multilingualism and multiculturalism being the norm means that Africans do not shy away from "crossing" ethnic, cultural and linguistic borders in their quest for voice and agency. Thus, language planning for multilingualism needs to take into account that languages spoken in a specific country are also spoken outside this country's borders, and that ethnic, cultural, linguistic, etc. borders are, in reality, social constructs. The idea is to build and extend multilingual democratic spaces for speakers as a way of enhancing and taking advantage of multilingualism as a voice for experience and identity performance, and hence as a linguistic resource. This would enable material production of multilingualism through local agency and voices across borders, be they ethnic, community-based or national. In this way, multiple languages would become tools for the social, political, cultural and economic transformation of Africa, as 
multilingualism becomes the means for increased socio-economic, political, etc. participation across broad African populations.

These considerations lead to the notion of 'linguistic repertoire-based multilingual models' (cf. Banda 2009a). Lastly, for status and corpus planning to be successful, regional organisations such as the African Union or Southern African Development Community - the latter a grouping of 15 southern African states which unite to address their shared challenges pertaining to education, socio-economics, health, security, etc. - need to become involved in language policy and planning in Africa, across borders (Banda 2008).

\section{References}

Anchimbe, E. 2007. On the distorting imposition of European templates on African sociolinguistic contexts. Available online: www.wikicfp.com/cfp/servlet/event. showcfp?eventid=165\&opyownerid=26 (Accessed 3 May 2009).

Appadurai, A. 1996. Modernity at large: Cultural dimensions of globalization. Minneapolis: University of Minnesota Press.

Asante, M.K. 2006. The rhetoric of globalization: The Europeanization of human ideas. Journal of Multicultural Discourses 1(2): 152-158.

Banda F. 2000. The dilemma of the mother tongue: Prospects for bilingual education in South Africa. Language, Culture and Curriculum 13(1): 51-66.

Banda, F. 2003. A survey of literacy practices in black and coloured communities in South Africa. Language, Culture and Curriculum 16(2): 173-184.

Banda, F. 2008. Orthography design and harmonization in development in Southern Africa. Open Space 2(3): 39-48.

Banda, F. 2009a. Towards multilingual models of education in South Africa. In K.K. Prah and B. Brock-Utne (eds.) Multilingualism: An African advantage. CASAS: Cape Town. pp. 102-118.

Banda, F. 2009b. Defying monolingual education: Alternative bilingual discourse practices in selected Cape Town Schools. "Language in Action" seminar series. Centre for Human Sciences, University of the Western Cape, 2 March 2009.

Ethnologue. 2009. Languages of the world. Dallas: SIL.

Gough, D. 1994. Myths of multilingualism: Democracy and democracy. Bua! 9(3): 9-11.

Gumperz, J. and D. Hymes. 1972. (eds.) Directions in sociolinguistics. New York: Holt, Rinehart and Winston.

Harries, P. 2007. Butterflies and barbarians: Swiss missionaries and systems of knowledge in South-East Africa. Oxford: James Currey.

Heller, M. 2007. Bilingualism: A social approach. London: Palgrave Macmillan.

Heugh, K. 2005. Teacher education issues: Implementation of a new curriculum and language in education policy. In N. Alexander (ed.) Mother tongue-based bilingual education in South Africa. Cape Town: Praesa. pp. 137-158.

Heugh, K. 2006. Language and literacy issues in South Africa. In N. Rassool (ed.) Global issues in language, education and development: Perspectives from postcolonial countries. Clevedon: Multilingual Matters. pp. 187-218.

Hymes, D. 1974. Foundations in sociolinguistics: An ethnographic approach. Philadelphia: University of Pennsylvania Press.

Jokweni, M. 2003. Two Nguni languages: A comparative analysis of orthography and terminology. In A. Chebanne, M. Jokweni, M.I Mokitimi and S. Ngubane (eds). Unifying Southern African languages. Cape Town: CASAS. pp. 163-172. 
Kachru, B. 1990. The alchemy of English. Illinois: University of Illinois Press.

Makoni, S. 1998a. African languages as European scripts: The shaping of communal memory. In S. Nuttall and C. Coetzee (eds.) Negotiating the past: The making of memory in South Africa. Cape Town: Oxford University Press. pp. 242-249.

Makoni, S. 1998b. In the beginning was the missionary's word: The European invention of African languages. In K.K. Prah (ed.) Between distinction and extinction: The harmonization and standardization of African languages. Cape Town: Casas. pp. 157-165.

Makoni, S., J. Brutt-Griffler and P. Mashiri. 2007. The use of "indigenous" and urban vernaculars in Zimbabwe. Language in Society 36: 25-49.

Myers-Scotton, C. 1993. Duelling languages. New York: OUP.

Peirce, B. and S. Ridge. 1997. Multilingualism in Southern Africa. Annual Review of Applied Linguistics 17: 170-190.

Phillipson, R. 1992. Linguistic imperialism. Oxford: OUP.

Prah, K.K. 1998. Introduction: The missing link in African education and development. In K.K. Prah (ed.) Between distinction and extinction: The harmonization and standardization of African languages. Johannesburg: Witwatersrand University Press. pp. 1-16.

Rassool, N. 2006. Global issues in language, education and development: Perspectives from postcolonial countries. Clevedon: Multilingual Matters.

Schmied, J. 1991. English in Africa. London: Longman.

Shi-xu 2007. Discourse studies and cultural politics. In Shi-xu (ed.) Discourse as cultural struggle. Hong Kong: Hong Kong University Press. pp. 3-15.

Stroud, C. 2008. Multilingualism and the future of Illwimi. Unpublished discussion document, Department of Linguistics, University of the Western Cape.

Williams, Q.E. 2008. The application of dual-medium and parallel-medium models of bilingual education at two primary schools in the Western Cape. Unpublished Master's thesis, Department of Linguistics, University of the Western Cape.

\section{Biographical note}

Felix Banda $(\mathrm{PhD})$ is a Professor in the Department of Linguistics at the University of the Western Cape, South Africa. His research interests include multilingualism in society and education, as well as Bantu morphology and syntax and language planning across geographical borders. His recent publications include 'The dilemma of the mother tongue: Prospects for bilingual education in South Africa'. Language, Culture and Curriculum 13(1): 51-66, 'What can we say when the English used has gone so high-tech?': Institutionalised discourse and interaction in development projects in a rural community in Kenya. Journal of Multicultural Discourses 4 (2) 165-181 [with Omondi Oketch], and a book Language Across Borders (Casas: Cape Town). 